\title{
Rammya Mathew: We must build capacity and infrastructure for effective quality improvement
}

\author{
Rammya Mathew GP \\ London
}

I've recently been considering whether quality improvement is as accessible as it's often made out to be. There's a pervading sense that anyone can attend a course and then have a go. But people actively involved in healthcare improvement will know that, if it's to be done well, it requires the understanding and application of improvement models, data science, and behavioural psychology. And, above all, quality improvement needs to be underpinned by strong clinical leadership.

By downplaying the technical and relational aspects of quality improvement, and by encouraging people to take on quality improvement without the right expertise, I fear that we may be doing the field of healthcare improvement a disservice. Mary Dixon-Woods alluded to this in her recent essay in The BMJ, ${ }^{1}$ which highlighted that even "plan-do-study-act" cycles (one of the most basic concepts in quality improvement) were mostly misused or misapplied.

We wouldn't expect our frontline staff to attend a half day course on research methods and then to set up a clinical trial in their own time. No-they do fellowships and doctorates, giving them both the funding and the time to do this and guaranteeing an adequate level of supervision. Likewise, if we want quality improvement to be done with any rigour we need to invest in developing a high level of expertise among system leaders. Quality improvement is dependent on a bottom-up approach, so everyone needs an awareness and understanding of it-but we also need experts who can provide direction and strategy and ensure that we stay true to quality improvement methodology.

Staff need the right level of training for the improvement work they undertake. Attending courses is clearly not enough, however: quality improvement is about the practical application of theoretical frameworks, so there has to be some assessment of whether we're doing it right in practice.

This is partly about making sure that people have appropriate supervision, but it's also about creating more opportunities for peer review. Only recently has a more accessible platform emerged for the publication of quality improvement work, but I suspect that the vast majority still goes unpublished and is therefore not subject to wider scrutiny. Unlike clinical research it has limited grant funding, so individuals and organisations invest their resources in "doing" and rarely have the capacity to write up or present what they've done. But without robust peer review we risk perpetually churning out low quality "improvement" projects, which are labelled as quality improvement but are often far from it.

It's clear that we urgently need to review and develop the infrastructure to support quality improvement. Otherwise, we might mistakenly conclude that quality improvement doesn't actually improve quality in healthcare-but only because we've set ourselves up for failure.

Competing interests: I co-lead Islington GP Federation's Quality Improvement Team.

Provenance and peer review: Commissioned; not externally peer reviewed.

Dixon-Woods M. How to improve healthcare improvement-an essay by Mary Dixon-Woods. BMJ 2019;367:I5514. 10.1136/bmj.I5514 31575526

Published by the BMJ Publishing Group Limited. For permission to use (where not already granted under a licence) please go to http://group.bmj.com/group/rights-licensing/ permissions 